Article

\title{
Nucleophilicities of Lewis Bases B and Electrophilicities of Lewis Acids A Determined from the Dissociation Energies of Complexes B ...A Involving Hydrogen Bonds, Tetrel Bonds, Pnictogen Bonds, Chalcogen Bonds and Halogen Bonds
}

\author{
Ibon Alkorta 1,* (D) and Anthony C. Legon 2,* (D) \\ 1 Instituto de Química Médica (IQM-CSIC), Juan de la Cierva, 3, E-28006 Madrid, Spain \\ 2 School of Chemistry, University of Bristol, Cantock's Close, Bristol BS8 1TS, UK \\ * Correspondence: ibon@iqm.csic.es (I.A.); a.c.legon@bristol.ac.uk (A.C.L.); Tel.:+34-91-258-7516 (I.A.); \\ $+44-117-331-7708$ (A.C.L.)
}

Received: 3 October 2017; Accepted: 19 October 2017; Published: 23 October 2017

\begin{abstract}
It is shown that the dissociation energy $D_{\mathrm{e}}$ for the process $\mathrm{B} \cdots \mathrm{A}=\mathrm{B}+\mathrm{A}$ for 250 complexes B. . A composed of 11 Lewis bases $B\left(\mathrm{~N}_{2}, \mathrm{CO}, \mathrm{HC} \equiv \mathrm{CH}, \mathrm{CH}_{2}=\mathrm{CH}_{2}, \mathrm{C}_{3} \mathrm{H}_{6}, \mathrm{PH}_{3}, \mathrm{H}_{2} \mathrm{~S}, \mathrm{HCN}, \mathrm{H}_{2} \mathrm{O}\right.$, $\mathrm{H}_{2} \mathrm{CO}$ and $\mathrm{NH}_{3}$ ) and 23 Lewis acids ( $\mathrm{HF}, \mathrm{HCl}, \mathrm{HBr}, \mathrm{HC} \equiv \mathrm{CH}, \mathrm{HCN}, \mathrm{H}_{2} \mathrm{O}, \mathrm{F}_{2}, \mathrm{Cl}_{2}, \mathrm{Br}_{2}, \mathrm{ClF}, \mathrm{BrCl}, \mathrm{H}_{3} \mathrm{SiF}$, $\mathrm{H}_{3} \mathrm{GeF}, \mathrm{F}_{2} \mathrm{CO}, \mathrm{CO}_{2}, \mathrm{~N}_{2} \mathrm{O}, \mathrm{NO}_{2} \mathrm{~F}, \mathrm{PH}_{2} \mathrm{~F}, \mathrm{AsH}_{2} \mathrm{~F}, \mathrm{SO}_{2}, \mathrm{SeO}_{2}, \mathrm{SF}_{2}$, and $\mathrm{SeF}_{2}$ ) can be represented to good approximation by means of the equation $D_{\mathrm{e}}=c^{\prime} N_{\mathrm{B}} E_{\mathrm{A}}$, in which $N_{\mathrm{B}}$ is a numerical nucleophilicity assigned to $\mathrm{B}, E_{\mathrm{A}}$ is a numerical electrophilicity assigned to $\mathrm{A}$, and $c^{\prime}$ is a constant, conveniently chosen to have the value $1.00 \mathrm{~kJ} \mathrm{~mol}^{-1}$ here. The 250 complexes were chosen to cover a wide range of non-covalent interaction types, namely: (1) the hydrogen bond; (2) the halogen bond; (3) the tetrel bond; (4) the pnictogen bond; and (5) the chalcogen bond. Since there is no evidence that one group of non-covalent interaction was fitted any better than the others, it appears the equation is equally valid for all the interactions considered and that the values of $N_{\mathrm{B}}$ and $E_{\mathrm{A}}$ so determined define properties of the individual molecules. The values of $N_{\mathrm{B}}$ and $E_{\mathrm{A}}$ can be used to predict the dissociation energies of a wide range of binary complexes $\mathrm{B} \cdots$ A with reasonable accuracy.
\end{abstract}

Keywords: noncovalent bonds; binary complexes; dissociation energies; nucleophilicity; electrophilicity; $a b$ initio calculations; geometry

\section{Introduction}

The best known, earliest identified non-covalent interaction is the hydrogen bond, although the halogen bond was discovered (but not so called) as long ago as 1869 through the reaction of iodine with ammonia [1]. The pioneering experiments of Hassel and co-workers in the late 1950s and early 1960s [2] led to the recognition of the halogen bridge (the term used by Hassel for the halogen bond). This was followed by a lull in experimental work until the mid-1990s when there was a very rapid growth of interest [3,4] in what then became known as the halogen bond. In the last 10 years, several new types of non-covalent interaction have been named, including the tetrel bond [5], the pnictogen bond [6] and the chalcogen bond [7], although it has been pointed out $[8,9]$ that these types of interaction were known for at least 30 years before they were assigned their current names.

Each non-covalent bond can be described $[9,10]$ in terms of the interaction of an electrophilic region of one molecule with a nucleophilic region of another molecule (or even the same molecule). In this article, we shall concentrate on the pairwise interaction B $\cdots$ A of a Lewis base molecule B (the provider of the nucleophilic site, usually a non-bonding (n) or a $\pi$-bonding electron pair) and 
a Lewis acid A molecule (the provider of the electrophilic site). The electrophilic site in A can be identified variously as associated with a hydrogen atom (Group 1 of the Periodic Table), a tetrel atom (Group 14), a pnictogen atom (Group 15), a chalcogen atom (Group 16) or a halogen atom (Group 17); hence, the names assigned to the different types of non-covalent interaction. The electrophilic regions associated with halogen atoms in Lewis acids A were identified as positive regions on the molecular electrostatic surface potentials (MESP) by Clark, Murray and Politzer [11], who named the regions as $\sigma$-holes. Subsequently, $\sigma$-holes were similarly identified at or near Group 16 [12], 15 [13] and 14 [14] atoms in various Lewis acid molecules $\mathrm{A}$.

An important aim in attempting to obtain a deeper understanding of non-covalent interactions in complexes B . A A is to be able to predict the strength of the interaction in terms of the properties of the individual molecules B and A. Two measures of interaction strength have been recognized, namely the intermolecular stretching force constant $k_{\sigma}$ and the dissociation energy $D_{\mathrm{e}}$ for the process $\mathrm{B} \cdots \mathrm{A}=\mathrm{B}+\mathrm{A}$. The former is a measure of the energy $\frac{1}{2} k_{\sigma}$ required for a unit infinitesimal extension of the intermolecular bond from its equilibrium length, while the latter is the energy required for infinite extension of that bond. It was recognized some time ago [15] that experimental $k_{\sigma}$. values (determined, for example, by rotational spectroscopy [16] from centrifugal distortion constants) of weak hydrogen-bonded complexes $\mathrm{B} \cdots \mathrm{HX}(\mathrm{X}=\mathrm{F}, \mathrm{Cl}, \mathrm{Br}, \mathrm{CCH}$ or $\mathrm{CN})$ could be described by the following expression:

$$
k_{\sigma}=c N_{\mathrm{B}} E_{\mathrm{A}}
$$

in which $c=2.5 \mathrm{~N} \mathrm{~m}^{-1}$ (a conveniently chosen constant) and $N_{\mathrm{B}}$ and $E_{\mathrm{A}}$ are the numerical nucleophilicity and electrophilicity of the Lewis base $B$ and the Lewis acid A, respectively. It was shown later $[3,17]$ that Equation 1 also applied to halogen-bonded complexes $\mathrm{B} \cdots \mathrm{XY}$, where $\mathrm{XY}$ is a homo- or hetero-dihalogen molecule. A subsequent analysis [18] established that, for many hydrogen-bonded and halogen-bonded complexes B $\cdots \mathrm{HX}$ and $\mathrm{B} \cdots \mathrm{XY}$, the property $D_{\mathrm{e}}$ (not generally available from experiment, but readily calculated $a b$ initio) is directly proportional to the property $k_{\sigma}$ to a good level of accuracy and therefore that Equation 1 can be rewritten as

$$
D_{\mathrm{e}}=c^{\prime} N_{\mathrm{B}} E_{\mathrm{A}}
$$

where $c^{\prime}$ is another constant.

If the various types of non-covalent interaction referred to earlier can all be described through the interaction of a nucleophilic region of $\mathrm{B}$ with an electrophilic region of $\mathrm{A}$, it should be possible to use Equation (2) to define a scale of nucleophilicities and electrophilicities for a wide range of Lewis bases B and Lewis acids A, whether held together in the complex B . A by a hydrogen bond, a tetrel bond, a pnictogen bond, a chalcogen bond or a halogen bond. In this article, we test this hypothesis for 11 Lewis bases and 23 Lewis acids. Thus, the values of $D_{\mathrm{e}}$ for 250 complexes B ‥ A covering the whole range of interaction types have been calculated ab initio at a high level of theory and fitted to Equation (2) (with the convenient choice $c^{\prime}=1.00 \mathrm{~kJ} \mathrm{~mol}^{-1}$ ) to yield $N_{\mathrm{B}}$ and $E_{\mathrm{A}}$ values for the individual molecules. It is concluded that Equation (2) does indeed lead to a reliable scale of nucleophilicities and electrophilicities for the specified Lewis bases and acids.

\section{Computational Methods}

The geometries of the isolated monomers and complexes have been optimized at the MP2/aug-cc-pVTZ computational level [19-21] with the Gaussian-09 program [22]. Frequency calculations at the same level have been carried out to confirm that the resulting geometry corresponds to an energy minimum. Using these geometries, a series of calculations have been performed to derive the complete basis set (CBS) extrapolation at MP2 level. In addition, CCSD(T)/aug-cc-pVTZ calculations [23] have been carried out with the MOLPRO program [24] to derive the CCSD(T)/CBS energy. The extrapolation scheme is divided in the three parts. The first one corresponds to the Hartree-Fock (HF) contribution that is obtained using the aug-cc-pVTZ (AVTZ, X = 3) in 
Equations (3)-(6), aug-cc-pVQZ (AVQZ, X = 4) and aug-ccV5Z (AV5Z, X = 5) and Equations 1,2 [25]. In the second part, the MP2 correlation contribution is derived from the results obtained with MP2/aug-cc-pVTZ and MP2/aug-cc-pVQZ calculations and applying Equations (5)-(7) [26]. In the third part, higher order contributions are obtained as the difference of the CCSD(T)/aug-cc-pVTZ and MP2/aug-cc-pVTZ energies (Equation (6)) [27,28]. Finally, a CCSD(T)/CBS quality energy is generated by adding the $E_{\mathrm{CBS}}^{\mathrm{HF}}, E_{\mathrm{CBS}}^{\mathrm{MP} 2 c o r r}$ and $\Delta E_{\mathrm{AVTZ}}^{\mathrm{CCSD}(\mathrm{T})}$ (Equation (9)). The latter energy has been obtained for all systems and used to calculate the dissociation energy, $D_{\mathrm{e}}$, of the complexes as the difference of the energy of the complex and the sum of the isolated monomers in their minimum geometry.

$$
\begin{aligned}
& E_{X}^{\mathrm{HF}}=E_{\mathrm{CBS}}^{\mathrm{HF}}+A e^{-\mathrm{BX}} \\
& E_{\mathrm{CBS}}^{\mathrm{HF}}=E_{\mathrm{AVTZ}}^{\mathrm{HF}}-\frac{\left(E_{\mathrm{AVTZ}}^{\mathrm{HF}}-E_{\mathrm{AVQZ}}^{\mathrm{HF}}\right)^{2}}{\left(E_{\mathrm{AVTZ}}^{\mathrm{HF}}-2 E_{\mathrm{AVQZ}}^{\mathrm{HF}}+E_{\mathrm{AV} 5 \mathrm{HZ}}^{\mathrm{HF}}\right)} \\
& E_{\mathrm{X}}^{\mathrm{MP} 2 \mathrm{corr}}=E_{\mathrm{X}}^{\mathrm{MP2}}-E_{\mathrm{X}}^{\mathrm{HF}} \\
& E_{\mathrm{X}}^{\mathrm{MP2corr}}=E_{\mathrm{CBS}}^{\mathrm{MP2} \text { corr }}+A X^{-3} \\
& E_{\mathrm{CBS}}^{\mathrm{MP2corr}}=\frac{4^{3} E_{\mathrm{AVQZ}}^{\mathrm{MP2}}-3^{3} E_{\mathrm{AVTZ}}^{\mathrm{MP2} \text { corr }}}{4^{3}-3^{3}} \\
& \Delta E_{\mathrm{AVTZ}}^{\mathrm{CCSD}(\mathrm{T})}=E_{\mathrm{AVTZ}}^{\mathrm{CCSD}(\mathrm{T})}-E_{\mathrm{AVTZ}}^{\mathrm{MP2}} \\
& E_{\mathrm{CBS}}^{\mathrm{CCSD}(\mathrm{T})}=E_{\mathrm{CBS}}^{\mathrm{HF}}+E_{\mathrm{CBS}}^{\mathrm{MP} 2 \text { corr }}+E_{\mathrm{AVTZ}}^{\mathrm{CCSD}(\mathrm{T})}
\end{aligned}
$$

The $D_{\mathrm{e}}$ energies of all the complexes have been used to fit simultaneously the nucleophilicities and electrophilicities of the Lewis bases and Lewis acids studied by means of Equation (10).

$$
D_{\mathrm{e}}=\left(\sum_{i=1}^{\text {Lewis bases }} x_{i} \times N_{\mathrm{B} i}\right) \times\left(\sum_{j=1}^{\text {Lewis acids }} x_{j} \times E_{\mathrm{A} j}\right)
$$

The values of $x_{i}$ and $x_{j}$ are 1.0 when the corresponding Lewis base or Lewis acid is present in the complex, and 0.0 if it is absent.

The molecular electrostatic surface potentials (MESP) of the isolated Lewis bases and Lewis acids in their minimum-energy configurations have been calculated at the MP2/aug-cc-pVTZ computational level and analyzed with the Multiwfn [29,30] and DAMQT [31] programs. In the Lewis acids, the maximum value on the 0.001 au electron density isosurface associated with the interaction, $V_{\mathrm{S} \text {,max }}$, has been characterized. For the Lewis bases, two different values have been obtained. The first one, in analogy with the Lewis acids, is the minimum on the 0.001 au electron density isosurface, $V_{\mathrm{S}, \min }$. The second value avoids the arbitrariness of the isosurface value by evaluation of the real minimum, $V_{\min }$.

\section{Results}

Table 1 displays values of $N_{\mathrm{B}}$ for 11 Lewis bases and $E_{\mathrm{A}}$ for 23 Lewis acids obtained from a least-squares fit of $D_{\mathrm{e}}$ values calculated ab initio for 250 binary complexes B $\cdots$ A by using Equation (10). We actually carried out calculations of $D_{\mathrm{e}}$ for the all of the 264 possible complexes that can be formed from the following 11 molecules $B$ acting as Lewis bases: $\mathrm{N}_{2}, \mathrm{CO}, \mathrm{HC} \equiv \mathrm{CH}, \mathrm{CH}_{2}=\mathrm{CH}_{2}, \mathrm{C}_{3} \mathrm{H}_{6}$ (cyclopropane), $\mathrm{PH}_{3}, \mathrm{H}_{2} \mathrm{~S}, \mathrm{HCN}, \mathrm{H}_{2} \mathrm{O}, \mathrm{H}_{2} \mathrm{CO}$ and $\mathrm{NH}_{3}$; and the following 24 molecules acting as Lewis acids: $\mathrm{HF}, \mathrm{HCl}, \mathrm{HBr}, \mathrm{HC} \equiv \mathrm{CH}, \mathrm{HCN}$, and $\mathrm{H}_{2} \mathrm{O}$ (constituting the hydrogen-bonded group); $\mathrm{F}_{2}, \mathrm{Cl}_{2}, \mathrm{Br}_{2}$, $\mathrm{ClF}$, and $\mathrm{BrCl}$ (the halogen-bonded group); $\mathrm{H}_{3} \mathrm{SiF}, \mathrm{H}_{3} \mathrm{GeF}, \mathrm{F}_{2} \mathrm{CO}$, and $\mathrm{CO}_{2}$ (the tetrel-bonded group); $\mathrm{N}_{2} \mathrm{O}, \mathrm{NO}_{2} \mathrm{~F}, \mathrm{PH}_{2} \mathrm{~F}$, and $\mathrm{AsH}_{2} \mathrm{~F}$ (the pnictogen-bonded group); and $\mathrm{SO}_{2}, \mathrm{SO}_{3}, \mathrm{SeO}_{2}, \mathrm{SF}_{2}$, and $\mathrm{SeF}_{2}$ (the chalcogen-bonded group). The resulting $D_{\mathrm{e}}$ values are given in Tables 2-6, respectively, for these various classes of non-covalent interaction. The reasons that 14 values were excluded from the global 
fit were as follows: (1) The complex $\mathrm{H}_{3} \mathrm{P} \cdots \mathrm{ClF}$ is known [32] to have significant ion-pair character $\left[\mathrm{H}_{3} \mathrm{PCl}\right]^{+} \ldots \mathrm{Cl}^{-}$with an enhanced $D_{\mathrm{e}}$ as a consequence and was excluded; (2) It was clear that several of the 11 complexes containing $\mathrm{SO}_{3}$ as a Lewis acid considerably worsened the fit. We noted that each B $\cdots \mathrm{SO}_{3}$ complex had much a larger $D_{\mathrm{e}}$ value than any of its $\mathrm{B} \cdots$ A counterparts, possibly a sign of significant ionic character and accordingly these too were excluded from the fit; (3) The complexes $\mathrm{H}_{3} \mathrm{P} \cdots \mathrm{AsH}_{2} \mathrm{~F}$ and $\mathrm{H}_{3} \mathrm{P} \cdots \mathrm{PH}_{2} \mathrm{~F}$ were significant outliers when included in the fit, perhaps because in these complexes each molecule can act simultaneously as a Lewis acid and a Lewis base [6,33], in contrast to the rest of the complexes where each molecule has only a single role. The values in Table 1 indicate that the order of nucleophilicities of the Lewis bases is:

$\mathrm{N}_{2}<\mathrm{CO}<\mathrm{HC} \equiv \mathrm{CH} \sim \mathrm{PH}_{3}<\mathrm{CH}_{2}=\mathrm{CH}_{2} \sim \mathrm{C}_{3} \mathrm{H}_{6} \sim \mathrm{H}_{2} \mathrm{~S}<\mathrm{HCN}<\mathrm{H}_{2} \mathrm{O}<\mathrm{H}_{2} \mathrm{CO}<\mathrm{NH}_{3}$

For the hydrogen-bonded complexes, the order of the electrophilicities of the Lewis acids is:

$\mathrm{HF}<\mathrm{HBr} \sim \mathrm{HCl}<\mathrm{HCN} \sim \mathrm{H}_{2} \mathrm{O}<\mathrm{HC} \equiv \mathrm{CH}$

The order among the halogen-bonded systems is:

$\mathrm{ClF}>\mathrm{BrCl} \sim \mathrm{Br}_{2}>\mathrm{Cl}_{2}>\mathrm{F}_{2}$

Table 1. Values of nucleophilicities $N_{\mathrm{B}}$ of 11 Lewis bases $\mathrm{B}$ and electrophilicities $E_{\mathrm{A}}$ of 23 Lewis acids A obtained by fitting the dissociation energies $D_{\mathrm{e}}$ of 250 complexes B $\cdots$ A to Equation (10).

\begin{tabular}{cccccc}
\hline \multicolumn{2}{c}{ Lewis Base } & \multicolumn{2}{c}{ Lewis Acid } & \multicolumn{2}{c}{ Lewis Acid } \\
\hline $\mathbf{B}$ & $\boldsymbol{N}_{\mathbf{B}}$ & $\mathbf{A}$ & $\boldsymbol{E}_{\mathbf{A}}$ & $\mathbf{A}$ & $\boldsymbol{E}_{\mathbf{A}}$ \\
\hline $\mathrm{N}_{2}$ & 1.50 & $\mathrm{HF}$ & 6.75 & $\mathrm{SeO}_{2}$ & 5.76 \\
$\mathrm{C} \equiv \mathrm{O}$ & 2.12 & $\mathrm{HBr}$ & 4.59 & $\mathrm{SeF}_{2}$ & 6.69 \\
$\mathrm{HC} \equiv \mathrm{CH}$ & 3.13 & $\mathrm{HCl}$ & 4.36 & $\mathrm{SF}_{2}$ & 3.75 \\
$\mathrm{H}_{2} \mathrm{C}=\mathrm{CH}_{2}$ & 3.44 & $\mathrm{HC} \equiv \mathrm{N}$ & 3.71 & $\mathrm{SO}_{2}$ & 2.92 \\
$\mathrm{C}_{3} \mathrm{H}_{6}$ & 3.39 & $\mathrm{H}_{2} \mathrm{O}$ & 3.74 & $\mathrm{AsH}_{2} \mathrm{~F}$ & 5.04 \\
$\mathrm{PH}_{3}$ & 3.12 & $\mathrm{HC} \equiv \mathrm{CH}$ & 2.16 & $\mathrm{PH}_{2} \mathrm{~F}$ & 3.88 \\
$\mathrm{H}_{2} \mathrm{~S}$ & 3.43 & $\mathrm{ClF}$ & 5.18 & $\mathrm{NO}_{2} \mathrm{~F}$ & 2.55 \\
$\mathrm{HC}_{\mathrm{H}_{2} \mathrm{C}=\mathrm{O}}$ & 4.27 & $\mathrm{BrCl}$ & 4.77 & $\mathrm{~N}_{2} \mathrm{O}$ & 1.80 \\
$\mathrm{H}_{2} \mathrm{O}$ & 5.48 & $\mathrm{Br}$ & 4.40 & $\mathrm{GeH}_{3} \mathrm{~F}$ & 4.63 \\
$\mathrm{NH}_{3}$ & 4.89 & $\mathrm{Cl}$ & 2.71 & $\mathrm{SiH}_{3} \mathrm{~F}$ & 3.45 \\
& 7.52 & $\mathrm{~F}_{2}$ & 1.13 & $\mathrm{~F}_{2} \mathrm{C}_{2} \mathrm{O}$ & 3.30 \\
& & & & $\mathrm{CO}_{2}$ & 2.15 \\
\hline
\end{tabular}

Table 2. Values of $D_{\mathrm{e}} /\left(\mathrm{kJ} \mathrm{mol}^{-1}\right)$ for 66 hydrogen-bonded complexes calculated ab initio.

\begin{tabular}{ccccccc}
\hline \multirow{2}{*}{ Lewis Base } & \multicolumn{7}{c}{ Lewis Acid } \\
\cline { 2 - 7 } & $\mathbf{H F}$ & $\mathbf{H B r}$ & $\mathbf{H C l}$ & $\mathbf{H C} \equiv \mathbf{N}$ & $\mathbf{H}_{\mathbf{2}} \mathbf{O}$ & $\mathbf{H C} \equiv \mathbf{C H}$ \\
\hline $\mathrm{N}_{2}$ & 10.34 & 6.21 & 5.81 & 5.37 & 5.43 & 3.40 \\
$\mathrm{CO}$ & 15.09 & 8.39 & 8.44 & 7.28 & 7.68 & 4.45 \\
$\mathrm{HC} \equiv \mathrm{CH}$ & 18.84 & 13.07 & 12.22 & 10.30 & 10.83 & 6.22 \\
$\mathrm{H}_{2} \mathrm{C}=\mathrm{CH}_{2}$ & 19.15 & 14.34 & 12.56 & 9.93 & 10.64 & 5.96 \\
$\mathrm{C}_{3} \mathrm{H}_{6}$ & 19.57 & 18.39 & 14.00 & 11.63 & 11.31 & 7.62 \\
$\mathrm{PH}_{3}$ & 20.15 & 12.90 & 12.97 & 10.10 & 10.13 & 5.51 \\
$\mathrm{H}_{2} \mathrm{~S}$ & 21.29 & 13.63 & 14.06 & 10.92 & 12.03 & 6.30 \\
$\mathrm{HC} \equiv \mathrm{N}$ & 31.99 & 20.06 & 19.60 & 20.09 & 16.92 & 10.56 \\
$\mathrm{H}_{2} \mathrm{C}=\mathrm{O}$ & 35.38 & 24.57 & 23.46 & 19.87 & 23.01 & 13.42 \\
$\mathrm{H}_{2} \mathrm{O}$ & 36.91 & 22.33 & 22.65 & 21.72 & 21.06 & 12.05 \\
$\mathrm{NH}_{3}$ & 52.81 & 36.69 & 34.75 & 27.28 & 27.07 & 15.15 \\
\hline
\end{tabular}


Table 3. Values of $D_{\mathrm{e}} /\left(\mathrm{kJ} \mathrm{mol}^{-1}\right)$ for 55 halogen-bonded complexes calculated ab initio.

\begin{tabular}{cccccc}
\hline \multirow{2}{*}{ Lewis Base } & \multicolumn{5}{c}{ Lewis Acid } \\
\cline { 2 - 6 } & $\mathbf{C l F}$ & $\mathbf{B r C l}$ & $\mathbf{B r}_{\mathbf{2}}$ & $\mathbf{C l}_{\mathbf{2}}$ & $\mathbf{F}_{\mathbf{2}}$ \\
\hline $\mathrm{N}_{2}$ & 7.35 & 7.98 & 7.93 & 4.20 & 2.33 \\
$\mathrm{CO}$ & 12.25 & 11.06 & 10.35 & 6.08 & 2.80 \\
$\mathrm{HC} \equiv \mathrm{CH}$ & 15.96 & 16.23 & 15.38 & 8.99 & 3.89 \\
$\mathrm{H}_{2} \mathrm{C}=\mathrm{CH}_{2}$ & 18.79 & 19.14 & 18.33 & 10.16 & 4.31 \\
$\mathrm{C}_{3} \mathrm{H}_{6}$ & 14.46 & 18.16 & 18.36 & 10.18 & 4.92 \\
$\mathrm{PH}_{3}$ & 38.56 & 19.35 & 17.85 & 10.28 & 3.54 \\
$\mathrm{H}_{2} \mathrm{~S}$ & 21.36 & 18.56 & 16.58 & 10.63 & 4.02 \\
$\mathrm{HC} \equiv \mathrm{N}$ & 20.28 & 18.87 & 17.56 & 10.93 & 4.82 \\
$\mathrm{H}_{2} \mathrm{C}=\mathrm{O}$ & 24.70 & 22.76 & 21.02 & 13.69 & 6.16 \\
$\mathrm{H}_{2} \mathrm{O}$ & 22.11 & 19.95 & 18.06 & 11.97 & 5.20 \\
$\mathrm{NH}_{3}$ & 43.96 & 35.37 & 31.63 & 19.98 & 7.57 \\
\hline
\end{tabular}

Table 4. Values of $D_{\mathrm{e}} /\left(\mathrm{kJ} \mathrm{mol}^{-1}\right)$ for 44 tetrel-bonded complexes calculated ab initio.

\begin{tabular}{ccccc}
\hline \multirow{2}{*}{ Lewis Base } & \multicolumn{4}{c}{ Lewis Acid } \\
\cline { 2 - 5 } & $\mathbf{G e H}_{\mathbf{3}} \mathbf{F}$ & $\mathbf{S i H}_{\mathbf{3}} \mathbf{F}$ & $\mathbf{F}_{\mathbf{2}} \mathbf{C}=\mathbf{O}$ & $\mathbf{C O}_{\mathbf{2}}$ \\
\hline $\mathrm{N}_{2}$ & 8.02 & 5.36 & 6.11 & 4.11 \\
$\mathrm{CO}$ & 10.23 & 7.59 & 7.57 & 4.97 \\
$\mathrm{HC} \equiv \mathrm{CH}$ & 13.97 & 9.66 & 10.65 & 9.16 \\
$\mathrm{H}_{2} \mathrm{C}=\mathrm{CH}_{2}$ & 16.36 & 10.96 & 10.41 & 7.51 \\
$\mathrm{C}_{3} \mathrm{H}_{6}$ & 17.05 & 9.88 & 11.47 & 8.99 \\
$\mathrm{PH}_{3}$ & 13.86 & 11.53 & 8.90 & 5.26 \\
$\mathrm{H}_{2} \mathrm{~S}$ & 13.93 & 11.48 & 10.41 & 6.80 \\
$\mathrm{HC} \equiv \mathrm{N}_{\mathrm{H}_{2} \mathrm{C}=\mathrm{O}}^{22.05}$ & 14.92 & 14.72 & 9.27 \\
$\mathrm{H}_{2} \mathrm{O}$ & 25.09 & 18.87 & 21.49 & 12.96 \\
$\mathrm{NH}_{3}$ & 22.04 & 16.41 & 17.67 & 12.38 \\
& 34.42 & 27.67 & 21.74 & 12.90 \\
\hline
\end{tabular}

Table 5. Values of $D_{\mathrm{e}} /\left(\mathrm{kJ} \mathrm{mol}^{-1}\right)$ for 44 pnictogen-bonded complexes calculated ab initio.

\begin{tabular}{ccccc}
\hline \multirow{2}{*}{ Lewis Base } & \multicolumn{4}{c}{ Lewis Acid } \\
\cline { 2 - 5 } & $\mathbf{A s H}_{\mathbf{2}} \mathbf{F}$ & $\mathbf{P H}_{\mathbf{2}} \mathbf{F}$ & $\mathbf{N O}_{\mathbf{2}} \mathbf{F}$ & $\mathbf{N}_{\mathbf{2}} \mathbf{O}$ \\
\hline $\mathrm{N}_{2}$ & 8.11 & 6.33 & 5.93 & 4.06 \\
$\mathrm{CO}$ & 12.41 & 10.00 & 7.19 & 4.77 \\
$\mathrm{HC} \equiv \mathrm{CH}$ & 17.54 & 13.73 & 8.31 & 8.33 \\
$\mathrm{H}_{2} \mathrm{C}=\mathrm{CH}_{2}$ & 20.62 & 14.88 & 10.33 & 7.04 \\
$\mathrm{C}_{3} \mathrm{H}_{6}$ & 17.23 & 11.44 & 10.75 & 8.35 \\
$\mathrm{PH}_{3}$ & 27.79 & 20.90 & 7.00 & 4.05 \\
$\mathrm{H}_{2} \mathrm{~S}$ & 17.50 & 14.55 & 8.02 & 5.88 \\
$\mathrm{HC} \equiv \mathrm{N}_{\mathrm{H}_{2} \mathrm{C}=\mathrm{O}}^{22.76}$ & 16.69 & 12.51 & 8.11 \\
$\mathrm{H}_{2} \mathrm{O}$ & 26.28 & 21.81 & 15.15 & 9.76 \\
$\mathrm{NH}_{3}$ & 22.84 & 18.02 & 11.83 & 9.86 \\
& 36.37 & 27.53 & 15.79 & 10.37 \\
\hline
\end{tabular}


Table 6. Values of $D_{\mathrm{e}} /\left(\mathrm{kJ} \mathrm{mol}^{-1}\right)$ for 55 chalcogen-bonded complexes calculated ab initio.

\begin{tabular}{cccccc}
\hline \multirow{2}{*}{ Lewis Base } & \multicolumn{5}{c}{ Lewis Acid } \\
\cline { 2 - 6 } & $\mathbf{S O}_{\mathbf{3}}$ & $\mathbf{S e F}_{\mathbf{2}}$ & $\mathbf{S e O}_{\mathbf{2}}$ & $\mathbf{S F}_{\mathbf{2}}$ & $\mathbf{S O}_{\mathbf{2}}$ \\
\hline $\mathrm{N}_{2}$ & 6.30 & 8.95 & 7.21 & 5.24 & 0.92 \\
$\mathrm{CO}$ & 12.56 & 12.81 & 9.53 & 7.26 & 2.36 \\
$\mathrm{HC} \equiv \mathrm{CH}$ & 19.92 & 22.08 & 17.21 & 12.14 & 8.17 \\
$\mathrm{H}_{2} \mathrm{C}=\mathrm{CH}_{2}$ & 23.30 & 26.21 & 18.31 & 13.03 & 7.97 \\
$\mathrm{C}_{3} \mathrm{H}_{6}$ & 17.11 & 21.27 & 22.21 & 11.54 & 9.03 \\
$\mathrm{PH}_{3}$ & 43.73 & 23.27 & 14.86 & 11.72 & 8.71 \\
$\mathrm{H}_{2} \mathrm{~S}$ & 31.71 & 23.42 & 19.94 & 13.23 & 11.23 \\
$\mathrm{HC} \equiv \mathrm{N}_{\mathrm{H}_{2} \mathrm{C}=\mathrm{O}}^{28.48}$ & 25.16 & 21.40 & 14.82 & 10.86 \\
$\mathrm{H}_{2} \mathrm{O}$ & 43.80 & 36.64 & 37.14 & 21.95 & 19.53 \\
$\mathrm{NH}_{3}$ & 37.89 & 31.55 & 28.78 & 18.63 & 16.07 \\
& 99.23 & 51.06 & 42.70 & 28.14 & 22.20 \\
\hline
\end{tabular}

The electrophilicity of the molecules forming chalcogen bonds via Se atoms are significantly larger than those involving S. Likewise, the $\mathrm{AsH}_{2} \mathrm{~F}$ molecule has a larger electrophilicity and forms stronger pnictogen bonds than its $\mathrm{P}$ analogue, and the same order obtains for the propensity to form of tetrel bonds in $\mathrm{H}_{3} \mathrm{GeF}$ and $\mathrm{H}_{3} \mathrm{SiF}$ containing complexes.

A plot of $D_{\mathrm{e}}$ from the $a b$ initio calculations for the 250 complexes versus $D_{\mathrm{e}}$ values generated from Equation (10) by using the $N_{\mathrm{B}}$ and $E_{\mathrm{A}}$ values given in Table 1 is shown in Figure 1. The correlation coefficient is 0.959 and indicates strongly that Equation (10) represents a good approximation for the 250 complexes included in the fit, a group that includes the sub-classes of complex in which the non-covalent interaction is a hydrogen bond, a halogen bond, a tetrel bond, a pnictogen bond and a chalcogen bond. Thus, it appears that Equation (2) (and therefore Equation (10)) provides a method of assigning nucleophilicities and electrophilicities to Lewis bases and Lewis acids, respectively, when involved in a wide range of non-covalent interactions. Conversely, the $N_{\mathrm{B}}$ and $E_{\mathrm{A}}$ values provide a method of predicting $D_{e}$ for a given complex $\mathrm{B} \cdots \mathrm{A}$.

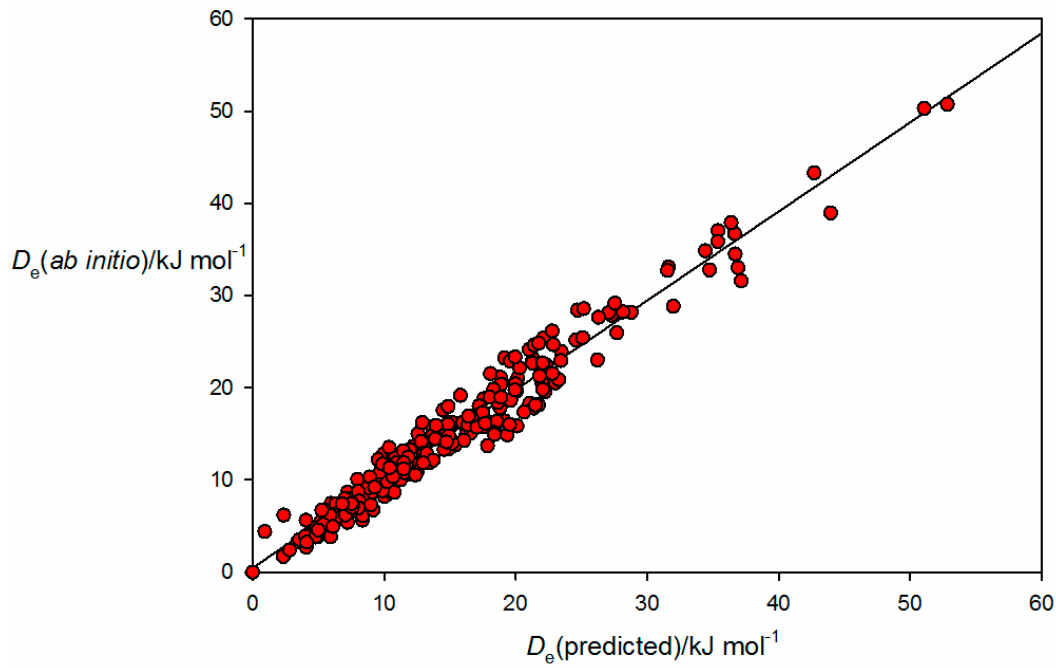

Figure 1. A graph of $D_{\mathrm{e}}$ values of 250 complexes B $\cdots$ A calculated $a b$ initio versus values of $D_{\mathrm{e}}$ predicted from the nucleophilicities $N_{\mathrm{B}}$ and electrophilicites $E_{\mathrm{A}}$ of the 11 Lewis bases and the 24 Lewis acids, respectively (see Table 1 ), involved in the complexes.

It is instructive to discuss the behavior of the ab initio calculated $D_{\mathrm{e}}$ values of the $\mathrm{B} \cdots$ A within a given non-covalent interaction type with the $N_{\mathrm{B}}$ values determined by the least-squares fit (see Table 1 ). This discussion will refer to the ab initio geometries of the six selected complexes shown in Figure 2. 
Figure 3 shows the plot of $D_{\mathrm{e}}$ versus $N_{\mathrm{A}}$ for 44 hydrogen bonded complexes $\mathrm{B} \cdots \mathrm{HX}$ formed from the 11 Lewis bases with $\mathrm{HF}, \mathrm{HCl}, \mathrm{HBr}$ and $\mathrm{HC} \equiv \mathrm{CH}$. The geometry determined for cyclopropane $\cdots \mathrm{HCl}$ is shown in Figure 2a, where it is seen that the $\mathrm{HCl}$ molecules lies along a median of the cyclopropane equilateral triangle and therefore the electrophilic $\mathrm{H}$ atom of $\mathrm{HCl}$ samples one of the pseudo- $\pi$ bonds of cyclopropane, in agreement with experiment [34]. Complexes involving $\mathrm{HCN}$ and $\mathrm{H}_{2} \mathrm{O}$ as the hydrogen donors are treated separately in Figure 4 because the points for the $\mathrm{B} \cdots \mathrm{HCN}$ and $\mathrm{B} \cdots \mathrm{HOH}$ complexes would be almost coincident with those associated with $\mathrm{B} \cdots \mathrm{HCl}$ and $\mathrm{B} \cdots \mathrm{HBr}$ if they were included in Figure 3. The individual straight lines represent the least-squares fit of the points for each B $\cdots H X$ series. The slope of each straight line is a measure of the electrophilicity of the given HX and corresponds approximately to the $E_{\mathrm{A}}$ value obtained in the global fit shown in Figure 1, as seen in Table 1.

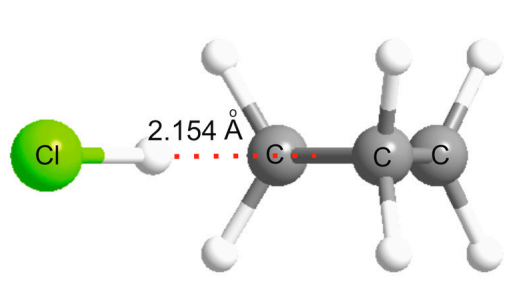

(a)

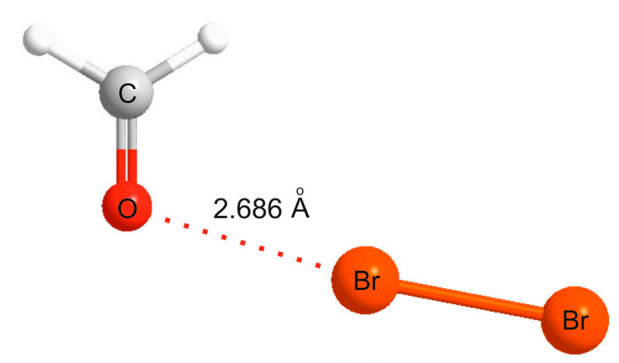

(b)

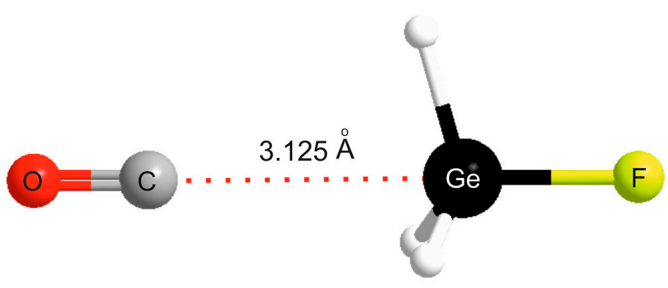

(c)

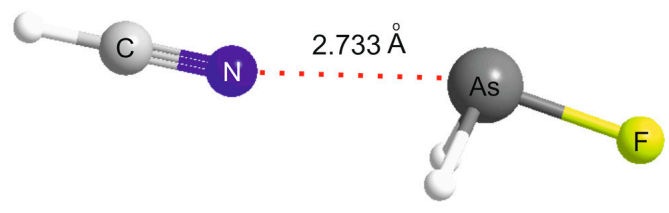

(e)

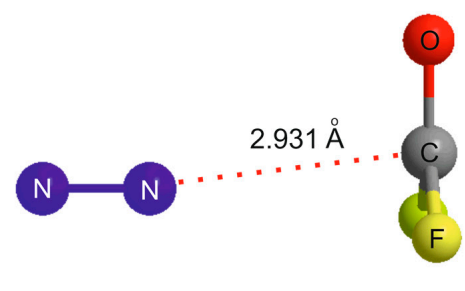

(d)

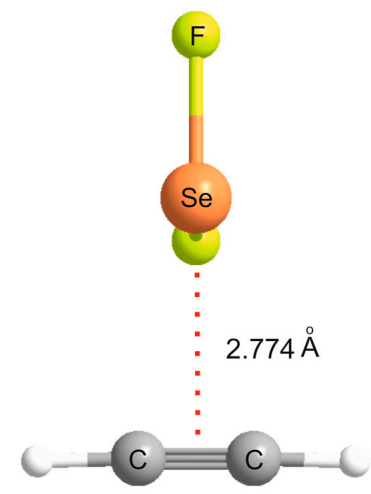

(f)

Figure 2. The geometries of selected complexes calculated $a b$ initio. They provides examples of the following classes of non-covalent bonds: (a) a hydrogen-bond; (b) a halogen-bond; (c,d) different types of tetrel bond; (e) a pnictogen bond; and (f) a chalcogen bond. These examples are cited in the text when Figures 3-8 are discussed. 


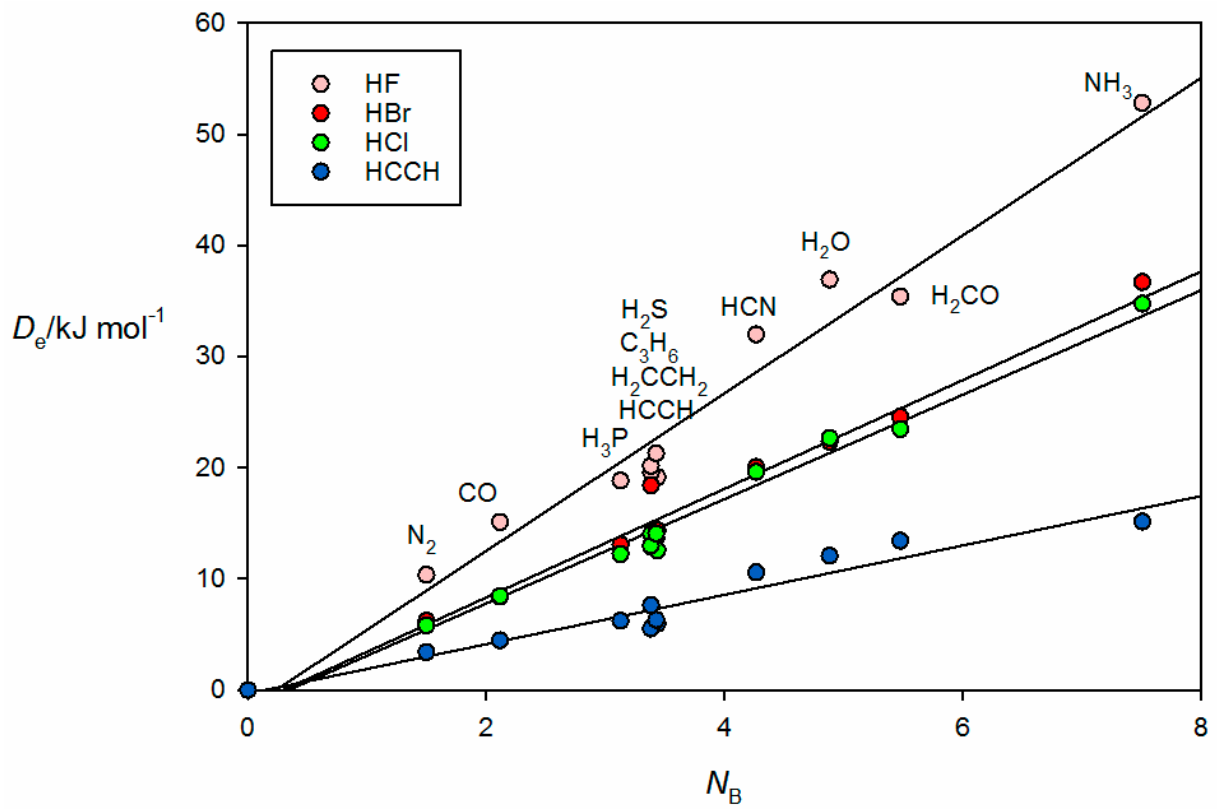

Figure 3. $D_{\mathrm{e}}$ versus $N_{\mathrm{B}}$ for the series of hydrogen-bonded complexes $\mathrm{B} \cdots \mathrm{HF}, \mathrm{B} \cdots \mathrm{HCl}, \mathrm{B} \cdots \mathrm{HBr}$ and B $\cdots \mathrm{HC} \equiv \mathrm{CH}$ (see Table 1 for $N_{\mathrm{B}}$ of the indicated Lewis bases B).

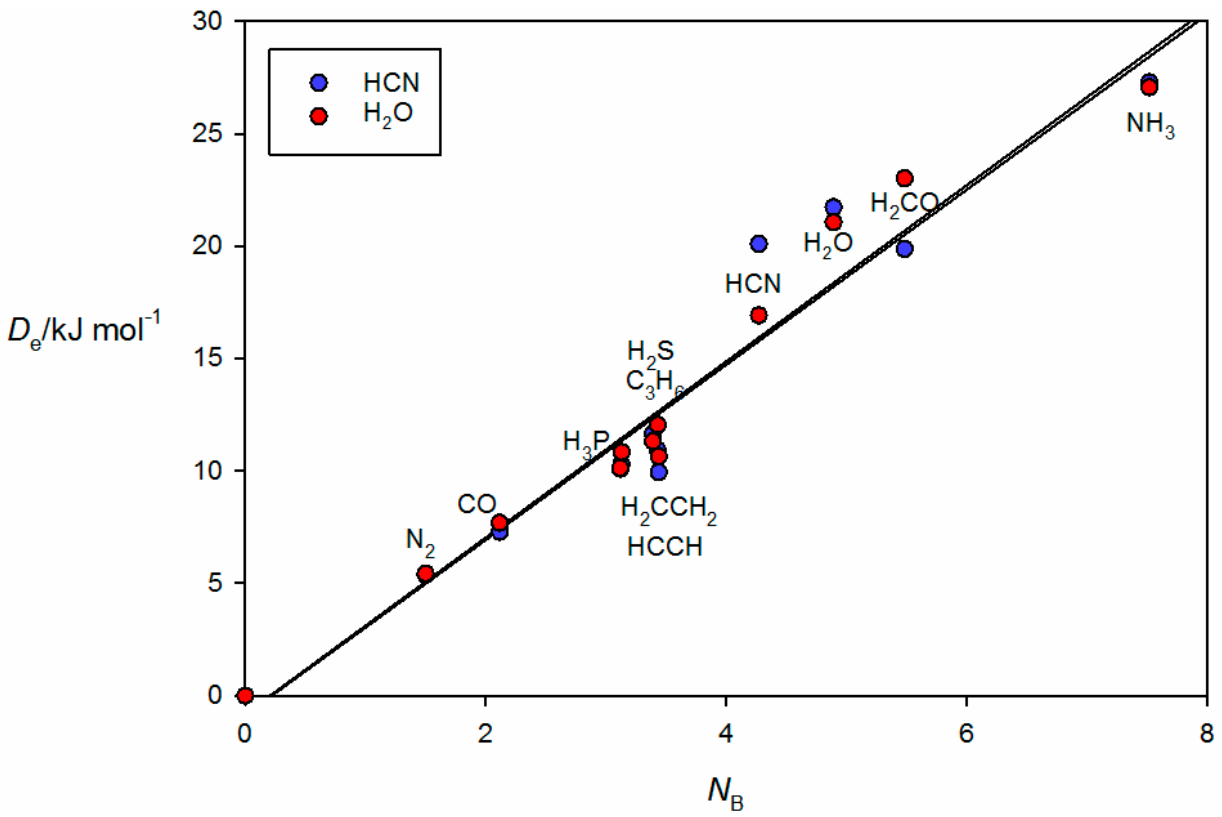

Figure 4. $D_{\mathrm{e}}$ versus $N_{\mathrm{B}}$ for the series of hydrogen-bonded complexes $\mathrm{B} \cdots \mathrm{HCN}$ and $\mathrm{B} \cdots \mathrm{HOH}$ (see Table 1 for $N_{\mathrm{B}}$ of the indicated Lewis bases $\mathrm{B}$ ).

We note that, in Figures 3 and 4, there is a bunching of the points for $\mathrm{B} \cdots \mathrm{HX}$, when $\mathrm{B}=\mathrm{PH}_{3}, \mathrm{H}_{2} \mathrm{~S}$, $\mathrm{HC} \equiv \mathrm{CH}, \mathrm{C}_{3} \mathrm{H}_{6}$ and $\mathrm{CH}_{2}=\mathrm{CH}_{2}$ for each $\mathrm{HX}$. The bunching is clearly systematic and independent of the $\mathrm{HX}$ molecule. Further, it is clear that the scatter of points from the appropriate straight line increases with the electrophilicity of HX.

The corresponding graph for the halogen-bonded complexes $\mathrm{B} \cdots \mathrm{ClF}, \mathrm{B} \cdots \mathrm{BrCl}, \mathrm{B} \cdots \mathrm{Br}_{2}, \mathrm{~B} \cdot \mathrm{Cl}_{2}$ and $\mathrm{B} \cdots \mathrm{F}_{2}$ is displayed in Figure 5. Note that, for reasons already given, the result for $\mathrm{H}_{3} \mathrm{P} \cdots \mathrm{ClF}$ is omitted. The systematic bunching of complexes involving $\mathrm{B}=\mathrm{PH}_{3}, \mathrm{H}_{2} \mathrm{~S}, \mathrm{HC} \equiv \mathrm{CH}_{3} \mathrm{C}_{3} \mathrm{H}_{6}$ and $\mathrm{CH}_{2}=\mathrm{CH}_{2}$ for each $\mathrm{XY}$ and the increased scatter as the electrophilicity of the Lewis acid increases are 
again apparent for the $\mathrm{B} \cdots \mathrm{XY}$. The geometry determined for $\mathrm{H}_{2} \mathrm{CO} \cdots \mathrm{Br}_{2}$ (see Figure $2 \mathrm{~b}$ ) suggests that the axial $\sigma$ hole at each $\mathrm{Br}$ atom in the $\mathrm{Br}_{2}$ molecule lies along the direction of a nonbonding electron pair (n pair) on $\mathrm{O}$, as conventionally envisaged. A similar geometry has been determined experimentally for $\mathrm{H}_{2} \mathrm{CO} \cdots \mathrm{ClF}$ [35]. Such interpretations led to sets of simple rules for predicting the geometries of hydrogen- and halogen-bonded complexes $[3,36]$.

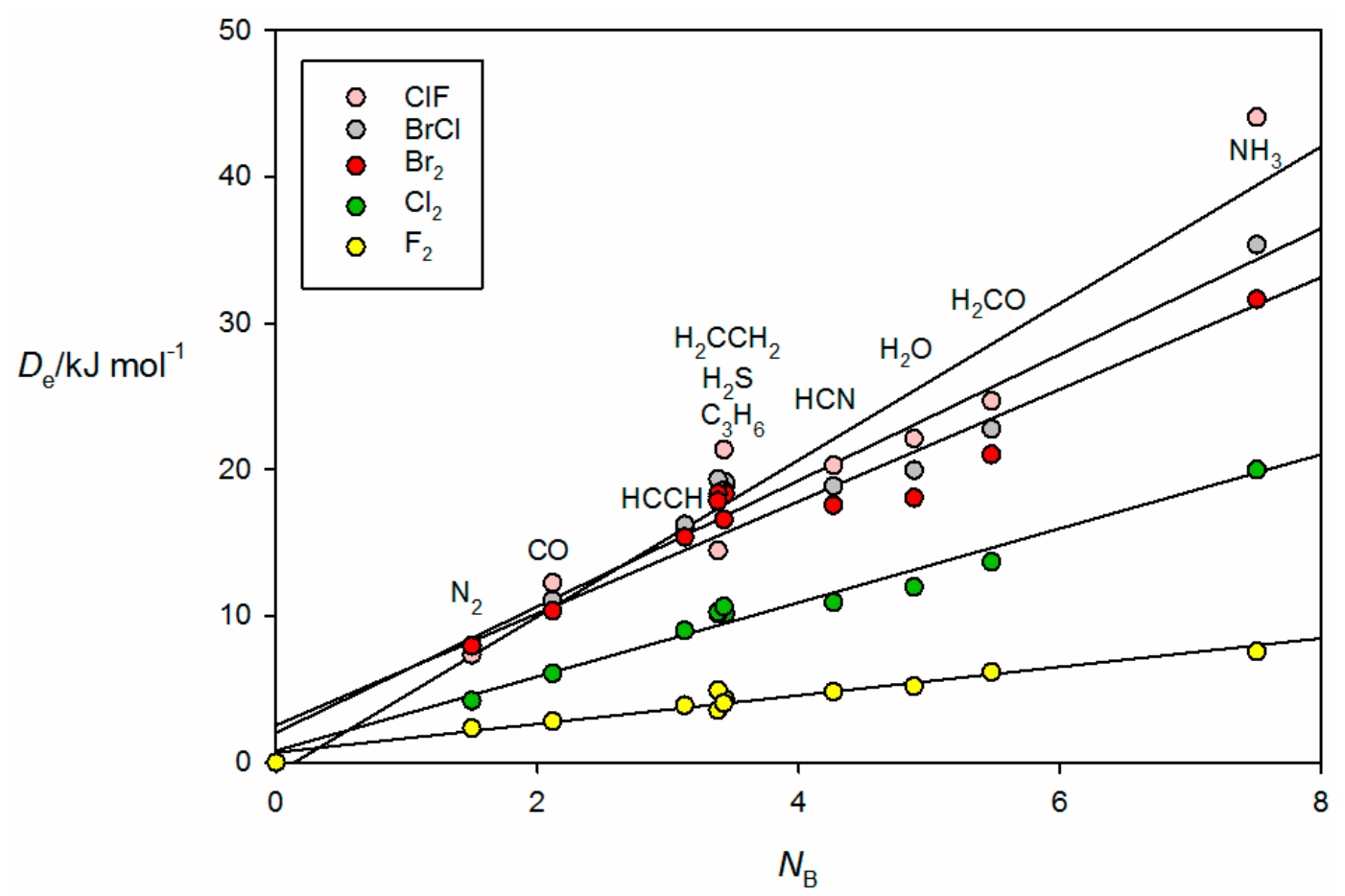

Figure 5. $D_{\mathrm{e}}$ versus $N_{\mathrm{B}}$ for the series of halogen-bonded complexes $\mathrm{B} \cdots \mathrm{XY}$, where $\mathrm{XY}=\mathrm{F}_{2}, \mathrm{Cl}_{2}, \mathrm{Br}_{2}$, $\mathrm{BrCl}$ and $\mathrm{ClF}$ (see Table 1 for the $N_{\mathrm{B}}$ values of the indicated Lewis bases $\mathrm{B}$ ).

Figure 6 gives the results for tetrel-bonded complexes $\mathrm{B} \cdots \mathrm{CO}_{2}, \mathrm{~B} \cdots \mathrm{H}_{3} \mathrm{SiF}, \mathrm{B} \cdots \mathrm{H}_{3} \mathrm{GeF}$ and $\mathrm{B} \cdots \mathrm{F}_{2} \mathrm{C}=\mathrm{O}$ when their $a b$ initio values of $D_{\mathrm{e}}$ are plotted against $N_{\mathrm{B}}$ of the 11 Lewis bases $\mathrm{B}$. For the B $\cdots \mathrm{H}_{3} \mathrm{SiF}$ and $\mathrm{B} \cdots \mathrm{H}_{3} \mathrm{GeF}$ complexes, the tetrel bond involves the $\mathrm{n}$ - or $\pi$-electron pairs of the Lewis base interacting with a $\sigma$ hole that lies near the $\mathrm{Si}$ or Ge atom on the $C_{3}$ axis, as can be clearly seen in the ab initio geometry determined for OC $\cdots \mathrm{H}_{3} \mathrm{GeF}$.shown in Figure 2c. The n-pair on the $\mathrm{C}$ atom of $\mathrm{OC}$ clearly interacts with the $\sigma$ hole at $\mathrm{Ge} . \mathrm{F}_{2} \mathrm{CO}$ forms tetrel bonds of a different type. This planar molecule has a $\pi$-hole at the carbon atom which is perpendicular to the molecular plane and the $\mathrm{n}$ - or $\pi$-pair of electrons of a Lewis base can interact with this, as is evident from the geometry determined for the $\mathrm{N}_{2} \cdots \mathrm{F}_{2} \mathrm{CO}$ complex displayed in Figure $2 \mathrm{~d}$. A $\pi$-hole at $\mathrm{C}$ is also involved in the tetrel bond in $\mathrm{B} \cdots \mathrm{CO}_{2}$. The systematic features identified for hydrogen- and halogen-bonded complexes in Figures 3-5 may also be seen in Figure 6. 


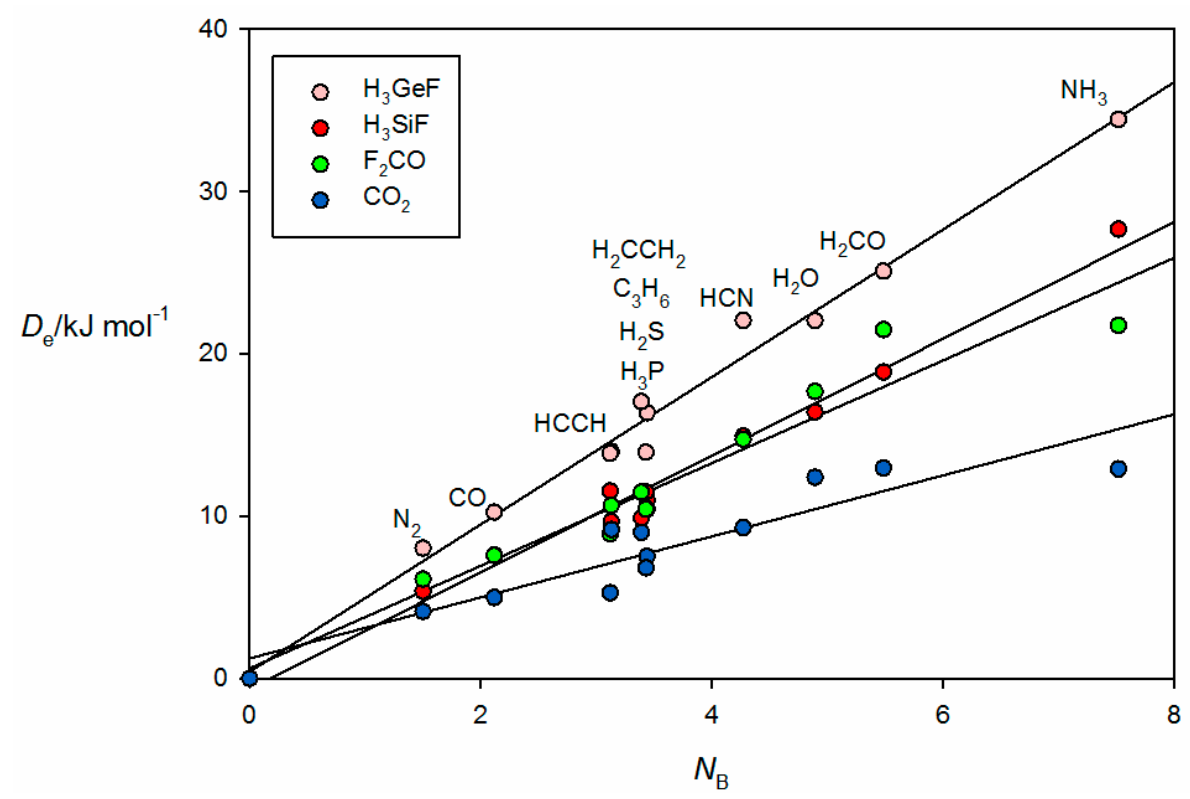

Figure 6. $D_{\mathrm{e}}$ versus $N_{\mathrm{B}}$ for the series of tetrel-bonded complexes $\mathrm{B} \cdots \mathrm{CO}_{2}, \mathrm{~B} \cdots \mathrm{H}_{3} \mathrm{SiF}, \mathrm{B} \cdots \mathrm{H}_{3} \mathrm{GeF}$ and $\mathrm{B} \cdots \mathrm{F}_{2} \mathrm{C}=\mathrm{O}$ (see Table 1 for the $N_{\mathrm{B}}$ values of the indicated Lewis bases $\mathrm{B}$ ).

The corresponding plots of $D_{\mathrm{e}}$ against $N_{\mathrm{B}}$ for the pnictogen-bonded complexes $\mathrm{B} \cdots \mathrm{PFH}_{2}$, $\mathrm{B} \cdots \mathrm{AsFH}_{2}, \mathrm{~B} \cdots \mathrm{NO}_{2} \mathrm{~F}$ and $\mathrm{B} \cdots \mathrm{N}_{2} \mathrm{O}$ are given in Figure 7 . The first two groups of pnictogen-bonded complexes utilize a $\sigma$ hole near $\mathrm{P}$ or As along the $\mathrm{P}-\mathrm{F}$ or As-F bond direction to form the non-covalent bond, while for the last two groups a $\pi$ hole at the central $\mathrm{N}$ atom fulfills the role. The ab initio geometry of $\mathrm{HCN} \cdots \mathrm{AsH}_{2} \mathrm{~F}$ in Figure 2e provides evidence of the $\sigma$-hole type of interaction. The pattern displayed by the $D_{\mathrm{e}}$ values of the pnictogen-bonded complexes in Figure 7 is similar to that seen in Figure 6 for the tetrel-bonded systems and again involves the characteristic bunching of points for the complexes in which $\mathrm{B}=\mathrm{PH}_{3}, \mathrm{H}_{2} \mathrm{~S}, \mathrm{HC} \equiv \mathrm{CH}, \mathrm{C}_{3} \mathrm{H}_{6}$ and $\mathrm{CH}_{2}=\mathrm{CH}_{2}$. Recall that, for reasons given earlier, complexes $\mathrm{H}_{3} \mathrm{P} \cdots \mathrm{PFH}_{2}$ and $\mathrm{H}_{3} \mathrm{P} \cdots \mathrm{AsFH}_{2}$ were excluded from the global fit in Figure 1 and therefore from Figure 7.

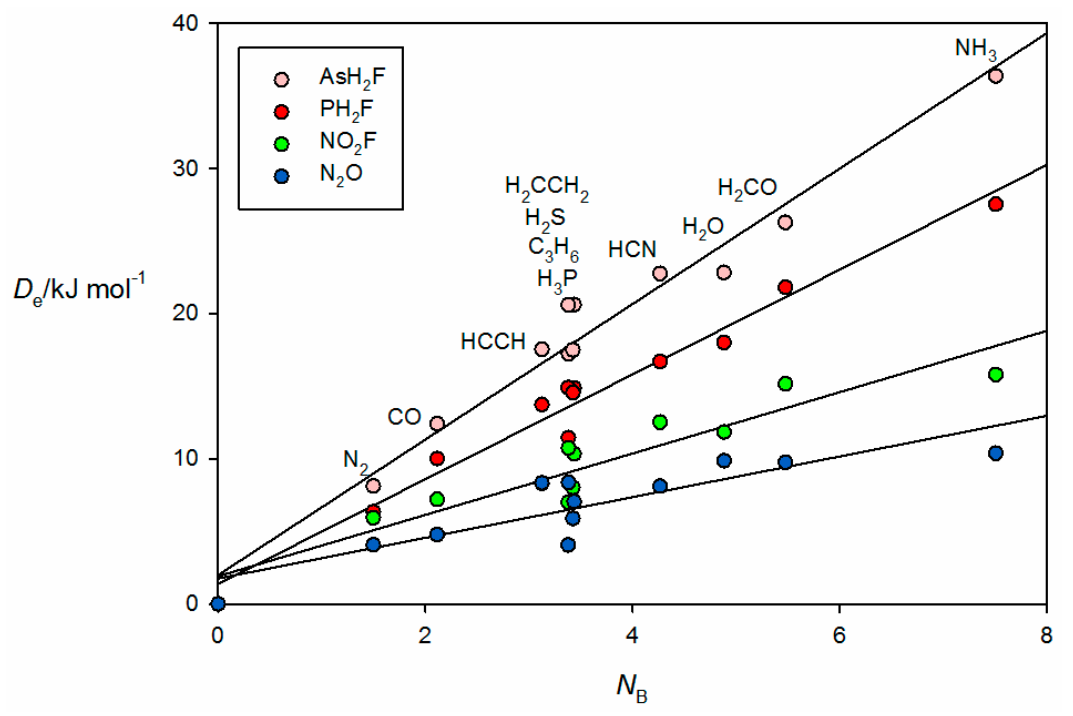

Figure 7. $D_{\mathrm{e}}$ versus $N_{\mathrm{B}}$ for the series of pnictogen-bonded complexes $\mathrm{B} \cdots \mathrm{PFH}_{2}, \mathrm{~B} \cdots \mathrm{AsFH}_{2}$, B. $\cdots \mathrm{NO}_{2} \mathrm{~F}$ and $\mathrm{B} \cdots \mathrm{N}_{2} \mathrm{O}$ (see Table 1 for the $N_{\mathrm{B}}$ values of the indicated Lewis bases $\mathrm{B}$ ). 
The familiar bunching pattern is again observed in Figure 8, in which the ab initio calculated values of $D_{\mathrm{e}}$ for complexes of the 11 Lewis bases $\mathrm{B}$ with each of the four Lewis acids $\mathrm{SF}_{2}, \mathrm{SeF}_{2}, \mathrm{SO}_{2}$ and $\mathrm{SeO}_{2}$ are plotted as a function of the $N_{\mathrm{B}}$ values of the various $\mathrm{B}$. The complexes here all involve chalcogen bonds. In the $\mathrm{B} \cdots \mathrm{SO}_{2}$ and $\mathrm{B} \cdots \mathrm{SeO}_{2}$, the chalcogen bond is between a $\pi$ hole at $\mathrm{S}$ or Se that is perpendicular to the plane containing the $\mathrm{SO}_{2}$ or $\mathrm{SeO}_{2}$ nuclei, but for $\mathrm{B} \cdots \mathrm{SF}_{2}$ and $\mathrm{B} \cdots \mathrm{SeF}_{2}$ a $\sigma$ hole near $\mathrm{S}$ or Se at the termination of a S-F or Se-F bond is involved, as seen from the ab initio geometry of the complex formed by the interaction of $\pi$ electrons of acetylene with the Se atom of $\mathrm{SeF}_{2}$ shown in Figure $2 \mathrm{f}$.

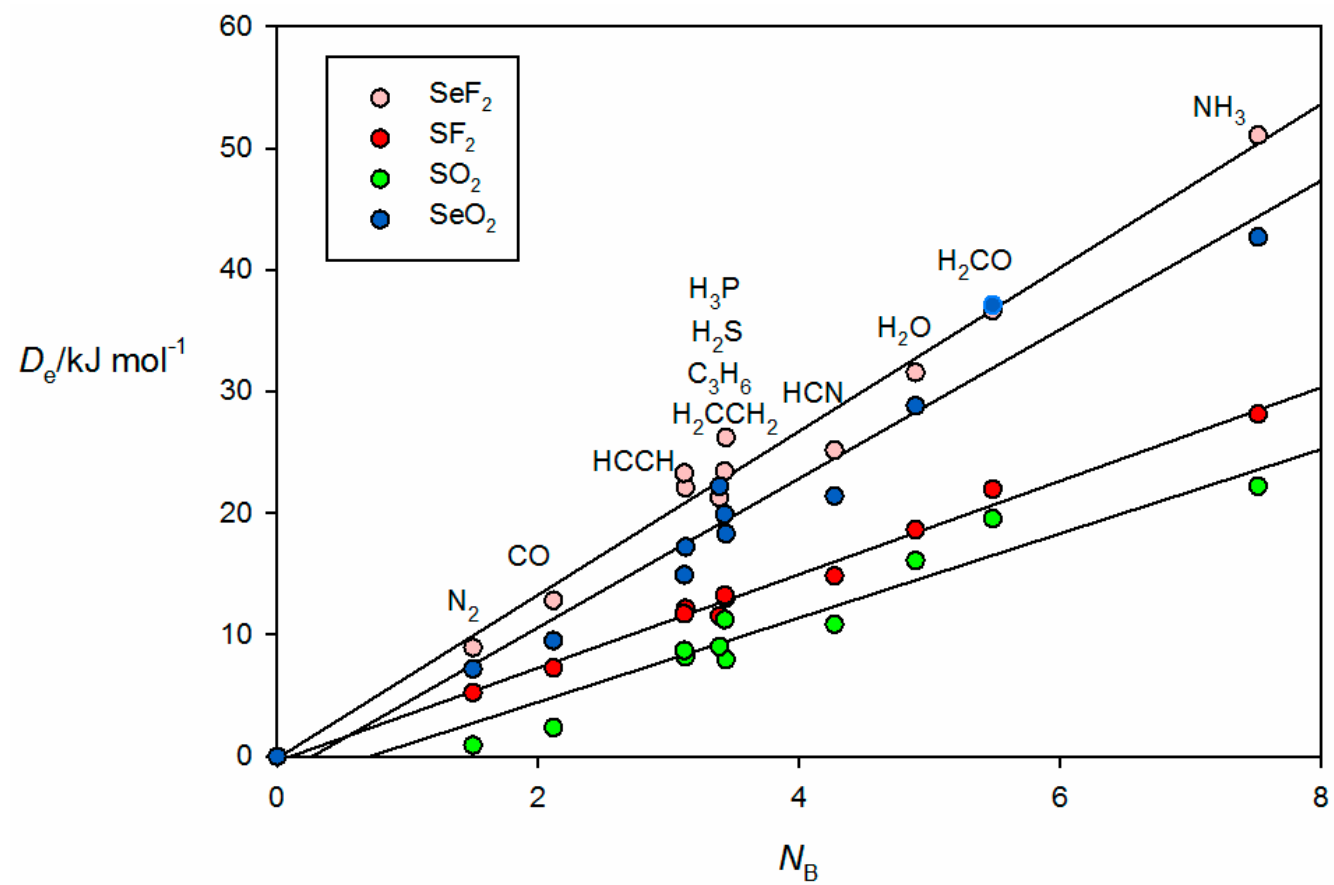

Figure 8. $D_{\mathrm{e}}$ versus $N_{\mathrm{B}}$ for the series of chalcogen-bonded complexes $\mathrm{B} \cdots \mathrm{SeF}_{2}, \mathrm{~B} \cdots \mathrm{SF}_{2}, \mathrm{~B} \cdots \mathrm{SO}_{2}$ and B. . SeO $\mathrm{SeO}_{2}$ (see Table 1 for the $N_{\mathrm{B}}$ values of the indicated Lewis bases $\mathrm{B}$ ).

It is of interest to ask whether there exists a linear relationship between the calculated $D_{\mathrm{e}}$ values and the intermolecular distances in the various complexes B $\cdots A$ investigated. For this purpose, the intermolecular distances of the hydrogen-bonded complexes have been gathered in Table 7 while the intermolecular distances for the rest of the complexes are given in Tables S1-S4 (Supplementary Materials). (The full optimized geometries of all the systems are gathered in Table S5 of the Supplementary Materials). When seeking a linear relationship between the calculated $D_{\mathrm{e}}$ values (given in Table 2) and the intermolecular distances of all complexes a poor $R^{2}$ value of 0.68 results. A more detailed analysis considering the individual hydrogen-bonded donors with all the bases $(n=11$ for each correlation) reveals values of $R^{2}$ between 0.80 and 0.53 (Table S6). Alternatively, looking to the correlation for a given base with the different HB donors ( $n=5$ for each correlation), leads to $R^{2}$ values between 0.94 and 0.53. Similar results are obtained for the rest of the interactions considered here (Table S6). Thus, it is clear that the $D_{\mathrm{e}}$ values and the intermolecular distances are poorly correlated for the systems considered and consequently cannot be used to predict each other. 
Table 7. Intermolecular distances $r(\mathrm{~B} \cdots \mathrm{H}) / \AA$ between the atom of the $\mathrm{B}$ and the $\mathrm{H}$ atom of A involved in the hydrogen-bond interaction in 66 hydrogen-bonded complexes.

\begin{tabular}{ccccccc}
\hline \multirow{2}{*}{ Lewis Base } & $\mathbf{7}$ Lewis Acid \\
\cline { 2 - 7 } & $\mathbf{H F}$ & $\mathbf{H B r}$ & $\mathbf{H C l}$ & $\mathbf{H C} \equiv \mathbf{N}$ & $\mathbf{H}_{\mathbf{2}} \mathbf{O}$ & $\mathbf{H C} \equiv \mathbf{C H}$ \\
\hline $\mathrm{N}_{2}$ & 2.055 & 2.342 & 2.297 & 2.412 & 2.318 & 2.499 \\
$\mathrm{C} \equiv \mathrm{O}$ & 2.057 & 2.355 & 2.301 & 2.490 & 2.337 & 2.600 \\
$\mathrm{HC} \equiv \mathrm{CH}$ & 2.125 & 2.301 & 2.292 & 2.498 & 2.348 & 2.602 \\
$\mathrm{H}_{2} \mathrm{C}=\mathrm{CH}_{2}$ & 2.129 & 2.309 & 2.297 & 2.540 & 2.367 & 2.645 \\
$\mathrm{C}_{3} \mathrm{H}_{6}$ & 2.024 & 2.158 & 2.154 & 2.314 & 2.421 & 2.249 \\
$\mathrm{PH}_{3}$ & 2.336 & 2.519 & 2.505 & 2.794 & 2.615 & 2.926 \\
$\mathrm{H}_{2} \mathrm{~S}$ & 2.268 & 2.434 & 2.416 & 2.670 & 2.513 & 2.795 \\
$\mathrm{HC} \equiv \mathrm{N}$ & 1.835 & 2.052 & 2.015 & 2.186 & 2.089 & 2.321 \\
$\mathrm{H}_{2} \mathrm{C}=\mathrm{O}$ & 1.708 & 1.840 & 1.830 & 2.075 & 1.972 & 2.225 \\
$\mathrm{H}_{2} \mathrm{O}$ & 1.704 & 1.893 & 1.863 & 2.044 & 1.945 & 2.188 \\
$\mathrm{NH}_{3}$ & 1.679 & 1.687 & 1.738 & 2.102 & 1.957 & 2.259 \\
\hline
\end{tabular}

Parameters used in the literature to rationalize the $D_{\mathrm{e}}$ values are the molecular electrostatic potential values of the isolated bases $\left(V_{\mathrm{S}, \min }\right.$ and $\left.V_{\min }\right)$ or acids $\left(V_{\mathrm{S}, \max }\right)$ (see Section 2. for the definitions of the various quantities $V$ ). The corresponding values have been gathered in Table S7. The comparison of the $D_{e}$ values of the complexes of each Lewis acids with the $V_{\mathrm{S} \text {, min }}$ or $V_{\min }$ of the Lewis bases ( $n=11$ for each correlation) provide $R^{2}$ values between 0.95 and 0.37 and between 0.97 and 0.43 , respectively. Alternatively, the relationship of the $\mathrm{V}_{\mathrm{S}, \max }$ of the Lewis acids with the corresponding $D_{e}$ values for a single Lewis base $(n=24)$ show $R^{2}$ values between 0.75 and 0.25 (Table S8). Attempts to use simultaneously $V_{\mathrm{S}, \min }$ of the Lewis bases and $V_{\mathrm{S} \text {, max }}$ of the Lewis acids in conjunction with the intermolecular distances for all the systems provide $R^{2}$ values smaller than 0.56 . As in the case of the intermolecular distances, these parameters do not seem to be useful as predictive tool, save in closely related systems.

\section{Conclusions}

It has been shown that the dissociation energy $D_{\mathrm{e}}$ for the reaction $\mathrm{B} \cdots \mathrm{A}=\mathrm{B}+\mathrm{A}$ for 250 complexes B ... A composed of 11 Lewis bases $B$ and 23 Lewis acids can be represented to good approximation by means of the equation $D_{\mathrm{e}}=c^{\prime} N_{\mathrm{B}} E_{\mathrm{A}}$, in which $N_{\mathrm{B}}$ is a numerical nucleophilicity assigned to $\mathrm{B}$, $E_{\mathrm{A}}$ is a numerical electrophilicity assigned to $\mathrm{A}$, and $c^{\prime}$ is a constant, conveniently chosen to have the value $1.00 \mathrm{~kJ} \mathrm{~mol}^{-1}$ here. The 250 complexes were chosen to cover a wide range of non-covalent interaction types, namely: (1) the hydrogen bond; (2) the halogen bond; (3) the tetrel bond; (4) the pnictogen bond; and (5) the chalcogen bond. There was no evidence that one group of non-covalent interaction was fitted any better than the others. Therefore, the equation appears to be equally valid for all the interactions considered here and the values of $N_{\mathrm{B}}$ and $E_{\mathrm{A}}$ determined in the manner discussed appear to be valid properties of the individual molecules. The values of $N_{\mathrm{B}}$ and $E_{\mathrm{A}}$ can therefore be used from to predict the dissociation energies of a wide range of binary complexes B $\cdots$ A with reasonable accuracy.

If the weak interaction in the complexes B $\cdots$ A considered here is predominantly electrostatic in nature, it seems reasonable that the individual molecular properties $N_{\mathrm{B}}$ and $E_{\mathrm{A}}$ are related to the molecular electrostatic surface potentials in the regions of the molecules to which these properties apply. We attempted to test this by examining the product of the maximum positive surface potential (to represent the electrophilic region of molecule A) and the maximum negative surface potential (to represent the nucleophilic region of molecule B) but the correlation was poor.

Supplementary Materials: The supplementary materials are available online. Table S1: Intermolecular distances $r(\mathrm{~B} \cdots \mathrm{X}) / \AA$ between the atom of the $\mathrm{B}$ and the $\mathrm{X}$ atom of $\mathrm{A}$ involved in the Halogen-bond interaction in 55 halogen-bonded complexes, Table S2: Intermolecular distances $r(\mathrm{~B} \cdots \mathrm{X}) / \AA$ A between the atom of the B and the T atom of A involved in the tetrel-bond interaction in 44 tetrel-bonded complexes, Table S3: Intermolecular distances 
$r(\mathrm{~B} \cdots \mathrm{X}) / \AA$ between the atom of the $\mathrm{B}$ and the $\mathrm{Z}$ atom of A involved in the pnictogen-bond interaction in 44 pnictogen-bonded complexes, Table S4: Intermolecular distances $r(\mathrm{~B} \cdots \mathrm{X}) / \AA$ between the atom of the $\mathrm{B}$ and the $\mathrm{Y}$ atom of $\mathrm{A}$ involved in the chalcogen-bond interaction in 55 chalcogen-bonded complexes, Table S5: Optimized geometries $\left(\AA,{ }^{\circ}\right)$ and energies (Hartree) at MP2/aug-cc-pVTZ computational level, Table S6: Linear correlations of $D_{e}$ vs. the interatomic distance ( $R^{2}$ coefficients), Table $S 7: V_{S, \min }$ and $V_{\min }$ of the Lewis Bases and $V_{S, \max }$ of the Lewis acids. The 0.001 au electron density isosurface has been chosen to calculate $V_{S, \min }$ and $V_{S \text {, max }}$, Table S8: Linear correlations of $D_{e}$ vs. the MEP parameters $\left(V_{S, \max } V_{S, \min }\right.$ and $\left.V_{\min }\right)\left(R^{2}\right.$ coefficients)

Acknowledgments: This work was carried out with financial support from the Ministerio de Economía y Competitividad (Project No. CTQ2015-63997-C2-2-P) and Comunidad Autónoma de Madrid (S2013/MIT2841, Fotocarbon). ACL thanks the School of Chemistry, University of Bristol for a Senior Research Fellowship.

Author Contributions: The authors contributed equally to the production of this article.

Conflicts of Interest: The authors declare no conflict of interest.

\section{References}

1. Guthrie, F. On the Iodide of Iodammonium. J. Chem. Soc. 1863, 16, 239-244. [CrossRef]

2. Hassel, O.; Rømming, C. Direct structural evidence for weak charge-transfer bonds in solids containing chemically saturated molecules. Quart. Rev. Chem. Soc. 1962, 16,1-18. [CrossRef]

3. Legon, A.C. Pre-reactive complexes of dihalogens XY with Lewis bases B in the gas phase: A systematic case for the 'halogen' analogue B...XY of the hydrogen bond B . . HX. Angew. Chem. Int. Ed. 1999, 111, 2850-2880. [CrossRef]

4. Metrangolo, P.; Resnati, G. Halogen bonding: A paradigm in supramolecular chemistry. Chem. Eur. J. 2001, 7, 2511-2519. [CrossRef]

5. Bauzá, A.; Mooibroek, T.J.; Frontera, A. Tetrel-Bonding Interaction: Rediscovered Supramolecular Force? Angew. Chem. Int. Ed. 2013, 52, 12317-12321. [CrossRef] [PubMed]

6. Zahn, S.; Frank, R.; Hey-Hawkins, E.; Kirchner, B. Pnicogen Bonds: A New Molecular Linker? Chem. Eur. J. 2011, 17, 6034-6038. [CrossRef] [PubMed]

7. Minyaev, R.M.; Minkin, V.I. Theoretical study of $\mathrm{O} \rightarrow \mathrm{X}(\mathrm{S}, \mathrm{Se}, \mathrm{Te})$ coordination in organic compounds. Can. J. Chem. 1998, 76, 776-778. [CrossRef]

8. Alcock, N.W. Secondary bonding to nonmetallic elements. Adv. Inorg. Chem. Radiochem. 1972, 15, 1-58.

9. Legon, A.C. Tetrel, pnictogen and chalcogen bonds identified in the gas phase before they had names: A systematic look at non-covalent interactions. Phys. Chem. Chem. Phys. 2017, 19, 14884-14896. [CrossRef] [PubMed]

10. Cavallo, G.; Metrangolo, P.; Pilati, T.; Resnati, G.; Terraneo, G. Naming Interactions from the Electrophilic Site. Cryst. Growth Des. 2014, 14, 2697-2702. [CrossRef]

11. Clark, T.; Hennemann, M.; Murray, J.S.; Politzer, P.A. Halogen bonding: The $\sigma$-hole. J. Mol. Model. 2007, 13, 291-296. [CrossRef] [PubMed]

12. Murray, J.S.; Lane, P.; Clark, T.; Politzer, P. Sigma-hole bonding: Molecules containing group VI atoms. J. Mol. Model. 2007, 13, 1033-1038. [CrossRef] [PubMed]

13. Murray, J.S.; Lane, P.; Politzer, P. A predicted new type of directional noncovalent interaction. Int. J. Quantum Chem. 2007, 107, 2286-2292. [CrossRef]

14. Murray, J.S.; Lane, P.; Politzer, P. Expansion of the sigma hole concept. J. Mol. Model. 2009, 15, 723-729. [CrossRef] [PubMed]

15. Legon, A.C.; Millen, D.J. Hydrogen bonding as a probe for electron densities: Limiting gas phase nucleophilicities and electrophilicities of B and HX. J. Am. Chem. Soc. 1987, 109, 356-358. [CrossRef]

16. Millen, D.J. Determination of stretching force constants of weakly bound dimers from centrifugal distortion constants. Can. J. Chem. 1985, 63, 1477-1479. [CrossRef]

17. Legon, A.C. The interaction of dihalogens and hydrogen halides with Lewis bases in the gas phase: An experimental comparison of the halogen bond and the hydrogen bond. Struct. Bond. 2008, 126, 17-64.

18. Legon, A.C. A reduced radial potential energy function for the halogen bond and the hydrogen bond in complexes B..XY and B..HX, where X and Y are halogen atoms. Phys. Chem. Chem. Phys. 2014, 16, 12415-12421, correction in 2014, 16, 25199-25199. [CrossRef] [PubMed]

19. Møller, C.; Plesset, M.S. Note on an Approximation Treatment for Many-Electron Systems. Phys. Rev. 1934, 46, 618-622. [CrossRef] 
20. Dunning, T.H. Gaussian-Basis Sets for Use in Correlated Molecular Calculations 1. The Atoms Boron through Neon and Hydrogen. J. Chem. Phys. 1989, 90, 1007-1023. [CrossRef]

21. Woon, D.E.; Dunning, T.H. Gaussian basis sets for use in correlated molecular calculations. V. Core-valence basis sets for boron through neon. J. Chem. Phys. 1995, 103, 4572-4585. [CrossRef]

22. Frisch, M.J.; Trucks, G.W.; Schlegel, H.B.; Scuseria, G.E.; Robb, M.A.; Cheeseman, J.R.; Scalmani, G.; Barone, V.; Mennucci, B.; Petersson, G.A.; et al. Gaussian 09; Gaussian Inc.: Wallingford, CT, USA, 2009.

23. Kümmel, H.G. A biography of the coupled cluster method. In Recent Progress in Many-Body Theories; WORLD SCIENTIFIC: Singapore, 2011; pp. 334-348.

24. Werner, H.-J.; Knowles, P.J.; Knizia, G.; Manby, F.R.; Schütz, M.; Celani, P.; Györffy, W.; Kats, D.; Korona, T.; Lindh, R.; et al. MOLPRO. version 2012.1, a package of ab initio programs.

25. Feller, D. The use of systematic sequences of wave functions for estimating the complete basis set, full configuration interaction limit in water. J. Chem. Phys. 1993, 98, 7059-7071. [CrossRef]

26. Halkier, A.; Klopper, W.; Helgaker, T.; Jørgensen, P.; Taylor, P.R. Basis set convergence of the interaction energy of hydrogen-bonded complexes. J. Chem. Phys. 1999, 111, 9157-9167. [CrossRef]

27. Tsuzuki, S.; Honda, K.; Uchimaru, T.; Mikami, M.; Tanabe, K. Origin of Attraction and Directionality of the $\pi / \pi$ Interaction: Model Chemistry Calculations of Benzene Dimer Interaction. J. Am. Chem. Soc. 2002, 124, 104-112. [CrossRef] [PubMed]

28. Ǩezáč, J.; Hobza, P. Describing Noncovalent Interactions beyond the Common Approximations: How Accurate Is the "Gold Standard," CCSD(T) at the Complete Basis Set Limit? J. Chem. Theor. Comput. 2013, 9, 2151-2155. [CrossRef] [PubMed]

29. Lu, T.; Chen, F. Multiwfn: A multifunctional wavefunction analyzer. J. Comput. Chem. 2012, 33, 580-592. [CrossRef] [PubMed]

30. Lu, T.; Chen, F. Quantitative analysis of molecular surface based on improved Marching Tetrahedra algorithm. J. Mol. Graphics Modell. 2012, 38, 314-323. [CrossRef] [PubMed]

31. Kumar, A.; Yeole, S.D.; Gadre, S.R.; López, R.; Rico, J.F.; Ramírez, G.; Ema, I.; Zorrilla, D. DAMQT 2.1.0: A new version of the DAMQT package enabled with the topographical analysis of electron density and electrostatic potential in molecules. J. Comput. Chem. 2015, 36, 2350-2359. [CrossRef] [PubMed]

32. Shaw, R.A.; Hill, J.G.; Legon, A.C. Halogen bonding with phosphine: Evidence for Mulliken inner complexes and the importance of relaxation energy. J. Phys. Chem. A 2016, 120, 8461-8468. [CrossRef] [PubMed]

33. Del Bene, J.E.; Alkorta, I.; Sanchez-Sanz, G.; Elguero, J. P_31_P_31 spin-spin coupling constants for pnicogen homodimers. Chem. Phys. Lett. 2011, 512, 184-187. [CrossRef]

34. Legon, A.C.; Aldrich, P.D.; Flygare, W.H. The rotational spectrum, chlorine nuclear quadrupole coupling constants, and molecular geometry of a hydrogen-bonded dimer of cyclopropane and hydrogen chloride. J. Am. Chem. Soc. 1982, 104, 1486-1490. [CrossRef]

35. Cooke, S.A.; Corlett, G.K.; Evans, C.M.; Legon, A.C.; Holloway, J.H. Angular geometries of complexes containing the OCl-F linkage: Rotational spectrum of formaldehyde-chlorine monofluoride. J. Chem. Phys. 1998, 108, 39-45. [CrossRef]

36. Legon, A.C.; Millen, D.J. Determination of properties of hydrogen-bonded dimers by rotational spectroscopy and a classification of dimer geometries. Faraday Discuss. Chem. Soc. 1982, 73, 71-87. [CrossRef]

Sample Availability: Not available. 